\title{
The association of nuclear abnormalities in exfoliated buccal epithelial cells with the health status of different agricultural activities farmers in Peninsular Malaysia
}

Zariyantey Abdul Hamid', Mohd Faizal Mohd Zulkifly ${ }^{1,3}$, Asmah Hamid', Syarif Husin Lubis ${ }^{1}$, Nihayah Mohammad', Ismarulyusda Ishak', Nur Zakiah Mohd Saat ${ }^{1}$, Hidayatul Fathi Othman'1, Ahmad Rohi Ghazali',

Mohd Jamil Mohd Rafaai ${ }^{1}$, Mohamad Roff Mohd Noor ${ }^{2}$ and Nor Fadilah Rajab ${ }^{1 *}$

\begin{abstract}
Background: Pesticide exposure possesses risk of genotoxicity to humans, particularly farmers. Despite accumulating evidences linking genotoxicity to pesticide exposure, epidemiological studies to address pesticide toxicity in occupationally exposed farmers in Malaysia remain underreported. Thus, this study was aimed to determine the presence of nuclear abnormalities through the assessment of micronucleus ( $M N$ ) and binucleus (BNu) frequencies in exfoliated buccal epithelial cells from farmers who were exposed to pesticides. A crosssectional study of farmers among different agricultural activities farmers in Bachok and Pasir Puteh, Kelantan, North East of Peninsular Malaysia was done to evaluate the presence of nuclear abnormalities and its correlation with their health status and farming activities.

Results: Analysis of buccal cells revealed that the frequency of MN was significantly higher $(p<0.05)$ in farmers as compared to controls. In contrast, no significant difference $(p>0.05)$ was observed for BNu frequency in between groups. Correlation analysis showed that apart from a significant $(p<0.05)$ and positive correlation between the duration of fertilizers exposure and frequencies of MN $(r=0.42, P=0.001)$ and $\mathrm{BNu}(r=0.37, P=0.02)$, no other correlation of various confounding factors on the formation of $\mathrm{MN}$ and $\mathrm{BNu}$ were observed.

Conclusion: In conclusion, pesticide and fertilizers exposure may contribute to the promotion of nuclear anomalies among Malaysian farmers who are engaged in mixed plantation activities. Further assessment of larger populations is important to address and overcome the potential risk of pesticide-induced genotoxicity.
\end{abstract}

Keywords: Pesticides, Farmers, Micronucleus, Binucleus, Buccal cells

\section{Background}

Worldwide, extensive use of pesticides in the agriculture sector can produce substantial threats to the environment and human health. Pesticides contain a great variety of components that differ in their composition and properties, with many that were classified as carcinogenic by the International Agency for Research on Cancer [1]. In the

\footnotetext{
* Correspondence: nfadilah@ukm.edu.my

${ }^{1}$ Biomedical Science Program, School of Diagnostic and Applied Health Sciences, Faculty of Health Sciences, Universiti Kebangsaan Malaysia (UKM,), Jalan Raja Muda Abdul Aziz, Kuala Lumpur 50300, Malaysia

Full list of author information is available at the end of the article
}

context of occupational exposure, farmers are the most at risk to health related-pesticide toxicity [2]. Long-term exposure to pesticides has been associated with a number of human health effects such as hormonal disruption, reproductive abnormalities, cancer, neurological disorders and cardiorespiratory symptoms [3-6].

The ability of pesticides to induce DNA damage has been reported in a number of studies [7-10] and a positive correlation between pesticides exposure and the genotoxicity risk has been previously documented [8, 11]. The findings suggested that exposure to pesticide can be genotoxic and carcinogenic to humans [12] 
which impose a need for genotoxicological biomonitoring in human populations who are at greater risk of pesticide-mediated toxicity.

Human biological monitoring offers a useful applied approach to evaluate potential genotoxic risk associated with exposure to various environmental genotoxicants. Cytogenetic damage such as formation of micronucleus $(\mathrm{MN})$, chromosomal aberration (CA) and sister chromatid exchange (SCE) has been widely used as biomarkers to indicate possible genotoxic risk of a defined exposure $[13,14]$. Among these, micronucleus testing is the most preferred approach due to it being less laborious, cheap and easy to apply in epidemiological studies $[15,16]$.

Evidences for increase in $\mathrm{MN}$ frequency in human population exposed to pesticide have been reported in several studies [17-19]. Cytogenetic monitoring is a widely accepted tool to estimate the genetic damage associated with pesticide exposure as is evident from its application in numerous epidemiological studies conducted to date [20-23].

$\mathrm{MN}$ is known as a product of acentric chromosomal fragments or fragments of the whole chromosomes left during mitotic cellular division which represent structural or numerical chromosomal aberrations (or both) during mitosis [24, 25]. In comparison, binucleated cells $(\mathrm{BNu})$ is defined as the presence of two nuclei that are adherent to each other and can indicate failure in cytokinesis [26]. Together, these biomarkers can allow detection of nuclear anomalies which indicate potential risk of pesticide-mediated genotoxicity. Sampling of exfoliated buccal epithelial cells were preferred due to its less laborious sample collection technique, a non- invasive approach and a sensitive method to monitor genetic damage among human populations [27, 28].

While pesticide exposure is known for its potential toxicity effects, epidemiological studies to address pesticide toxicity in occupationally exposed farmers in Malaysia remain underreported. Thus, this study is aimed to determine the presence of nuclear abnormalities through the assessment of $\mathrm{MN}$ and $\mathrm{BNu}$ frequencies in exfoliated buccal epithelial cells from farmers who were exposed to pesticides in Bachok and Pasir Puteh, Kelantan, North East of Peninsular Malaysia. Influence of various confounding factors which include the use of personal protective equipment (PPE), type of agriculture activities and demographic status on the frequencies of $\mathrm{MN}$ and $\mathrm{BNu}$ were also considered. Together, this study can provide information on the safety aspect of farming activities in Malaysia in order to promote appropriate pesticide handling practices in agriculture sectors.

\section{Methods}

\section{Study design}

A cross-sectional study was conducted in the East Coast of Peninsular Malaysia. The sample frame was a list of farmers as registered by the District Farmers Association of Bachok and Pasir Puteh. Systematic random sampling method was employed to recruit farmers and sample size estimation was determined using the method described in Cochran [29] based on the standard deviation from a study conducted by Pastor et al. [30]. The inclusion criteria for subjects' selection were farmers aged between 19 to 60 years old who have been working as a farmer for a minimum of 1 year and have never stopped working for more than 3 months in a year. The exclusion criteria were farmers who have a family history of cancer or have been diagnosed for any cancer. A structured questionnaire was used to gather information on socio-demographics, knowledge on safe pesticides handling practices, pesticides application and the use of personal protective equipment (PPE). The study was explained to the potential subjects and informed consent was obtained prior to buccal cell sampling. The questionnaire was administered face-to-face. The protocol of this study was approved by the Universiti Kebangsaan Malaysia Ethics Committee (UKMEC) (UKM1.5.3.5/244/ NN-201-2010). This study was conducted as part of a collaborative research with the Malaysian Agriculture and Research Development Institute (MARDI) on the health impact associated with pesticides exposure among farmers in Malaysia.

\section{Subjects}

The study was carried out on 39 farmers in Bachok ( $n=$ $11)$ and Pasir Puteh $(n=28)$, Kelantan. The areas were selected for its extensive use of pesticides and fertilizers with mixed plantation activities. The main crops grown were rice, tobacco and varieties of vegetables such as chillies, cucumbers and tapiocas. The control subjects have no record of pesticide exposure and were composed of 30 office staff from UKM Jalan Raja Muda Abdul Aziz campus, Federal Territory of Kuala Lumpur, Malaysia.

\section{Buccal cells collection}

Collection of buccal cells was performed according to the method as described in [30] with minor modifications. Briefly, prior to sample collection, subjects rinsed their mouth with water for removal of unwanted contaminants. Buccal cells were obtained by rubbing the buccal mucosa layer using a sterile wooden tongue depressor. The buccal cells were washed three times in $5 \mathrm{ml}$ buffered solution (0.003 M EDTA, $0.01 \mathrm{M}$ Tris$\mathrm{HCl}, 0.64 \mathrm{M} \mathrm{NaCl})$ at $\mathrm{pH} 7.0$ by centrifugation at $2000 \mathrm{rpm}$ for $10 \mathrm{~min}$ each, with a brief vortexing at every interval for dissociation of the cell pellets. After the third wash, cell pellets were added with $5 \mathrm{ml}$ of $0.075 \mathrm{M} \mathrm{KCL}$ and $50 \mu \mathrm{l}$ of $1 \% \mathrm{DMSO}$. The mixtures were incubated for $30 \mathrm{~min}$ at room temperature 
followed by the addition of $1 \mathrm{ml}$ of Carnoy fixative solution (methanol and acetic acid at a ratio of 3:1). The mixtures were then centrifuged at $2000 \mathrm{rpm}$ for $10 \mathrm{~min}$. Following removal of the supernatant, the cell pellets were fixed with $10 \mathrm{ml}$ Carnoy fixative solution and stored at $-20{ }^{\circ} \mathrm{C}$ until further analysis.

\section{Evaluation of micronuclei and binucleated buccal cells}

Fixed cell pellets were washed twice in $10 \mathrm{ml}$ Carnoy fixative solution at $2000 \mathrm{rpm}$ for $10 \mathrm{~min}$. At the second wash, most of the supernatants were discarded except a leftover solution of approximately $1 \mathrm{ml} .200 \mu \mathrm{l}$ of cell suspensions was dropped onto preheated $\left(37^{\circ} \mathrm{C}\right)$ and pre-cleaned frosted slides. The slides were allowed to air-dry for 5-10 min and stained with $0.0025 \%$ acridine orange (AO) for microscopic analysis. Cytological slides were prepared in triplicates for each subject. A total of 1000 cells were counted for each subject and the frequency of $\mathrm{MN}$ and $\mathrm{BNu}$ were determined using a fluorescence microscope (OLYMPUS XC50) at x200 and x400 magnifications.

\section{Stastical analysis}

Data were analysed using the SPSS statistical software package version 18.0. The level of significance was set as $p \leq 0.05$. Data were tested for normality using the Shapiro-Wilk test. Student's $t$-test was used for the analysis of differences between groups. The correlation between the two variables was analyzed using Pearson correlation.

\section{Results}

The demographic data of the studied population (Table 1) indicate that the majority of the farmers in Bachok and Pasir Puteh (56.4 \%) were aged between 56 to 65 years old while in the control group, the majority of subjects (40.0\%) were aged between 36 to 45 years old. Meanwhile, no remarkable differences were observed for both groups with regards to other general characteristics, which include educational background, smoking status and body mass index (BMI). The majority of farmers $(\mathrm{F})$ and control $(\mathrm{C})$ were pre-obese $(F=$ $51.3 \%$; $C=50.0 \%)$, completed secondary school $(F=$ $51.3 \% ; C=63.3 \%)$ and non-smokers $(F=56.4 \% ; C=$ $70.0 \%)$.

With respect to chronic diseases and health-associated symptoms (Table 2), farmers had higher percentages of hypertension (30.8\%), asthma (20.5\%) and gastric $(28.2 \%)$ as compared to that observed in the control group. Additionally, more than $50 \%$ of farmers claimed to frequently experience blurred vision and numbness. Other symptoms such as eye irritation, coughing, insomnia and runny nose were also found to be higher in farmers as compared to control.
Table 1 General characteristics of studied population

\begin{tabular}{|c|c|c|}
\hline \multirow[t]{2}{*}{ Characteristics } & Farmers & Controls \\
\hline & $n=39(\%)$ & $n=30(\%)$ \\
\hline \multicolumn{3}{|l|}{ Age groups } \\
\hline $26-35$ & $2(5.1)$ & $6(20.0)$ \\
\hline $36-45$ & $7(17.9)$ & $12(40.0)$ \\
\hline $46-55$ & $8(20.5)$ & 10(33.3) \\
\hline $56-65$ & $22(56.4)$ & $2(6.7)$ \\
\hline \multicolumn{3}{|l|}{ Gender } \\
\hline Male & 33(84.6) & $21(70.0)$ \\
\hline Female & $6(15.4)$ & $9(30.0)$ \\
\hline \multicolumn{3}{|l|}{ Education } \\
\hline None & $2(5.1)$ & $0(0)$ \\
\hline Primary school & 17(43.6) & $2(6.7)$ \\
\hline Secondary school & 20(51.3) & 19(63.3) \\
\hline University & $0(0)$ & $9(30.0)$ \\
\hline \multicolumn{3}{|l|}{ Smoking } \\
\hline Smokers & 17(43.6) & $9(30.0)$ \\
\hline Non-smokers & $22(56.4)$ & $21(70.0)$ \\
\hline \multicolumn{3}{|l|}{$B M I\left(\mathrm{~kg} / \mathrm{m}^{2}\right)$} \\
\hline Underweight (<18.5) & $4(10.3)$ & $0(0)$ \\
\hline Normal (18.5-24.9) & 13(33.3) & $9(30.0)$ \\
\hline Pre-obese (25.0-29.9) & 20(51.3) & $15(50.0)$ \\
\hline Obese grade 1 (30.0-34.9) & $2(5.1)$ & $3(10.0)$ \\
\hline Obese grade 2 (35.0-39.9) & $0(0)$ & $3(10.0)$ \\
\hline
\end{tabular}

Table 2 Commonly reported chronic diseases and health symptoms

\begin{tabular}{lll}
\hline & $\begin{array}{l}\text { Farmers } \\
n=39(\%)\end{array}$ & $\begin{array}{l}\text { Controls } \\
n=30(\%)\end{array}$ \\
\hline Chronic Diseases & & $5(16.7)$ \\
Hypertension & $12(30.8)$ & $3(10.0)$ \\
Diabetes Mellitus & $2(5.1)$ & $2(6.7)$ \\
Asthma & $8(20.5)$ & $3(10.0)$ \\
Gastric & $11(28.2)$ & \\
Health-associated symptoms & & $3(10.0)$ \\
Sore throat & $7(17.9)$ & $10(33.3)$ \\
Headache & $14(35.9)$ & $10(33.3)$ \\
Blurred vision & $22(56.4)$ & $1(3.3)$ \\
Insomnia & $6(15.4)$ & $7(23.3)$ \\
Eyes irritation & $17(43.6)$ & $1(3.3)$ \\
Runny nose & $6(15.4)$ & $2(6.7)$ \\
Numbness & $23(59.0)$ & $4(13.3)$ \\
Cough & $17(43.6)$ &
\end{tabular}


With regards to the application of personal protective equipments (PPE), a majority of farmers (Table 3) claimed the use of safety helmets (89.7\%), long-sleeved shirt (89.7 \%), long pants (97.4\%), nose mask (84.6\%) and boots $(71.8 \%)$ during pesticide handling. Meanwhile, usage of gloves was at a moderate level with only $53.8 \%$ who claimed to use it. Eye goggles were found to be the least used PPE with $69.2 \%$ of farmers who claimed that they never used eye goggles while handling pesticides.

Additional information with regards to farming activities were also evaluated. The information includes type of crops, farming experiences, duration of pestiside and fertilizers exposure and types of pesticide applicators being utilized. As shown in Table 4, the main crops grown were paddy, vegetables and tobacco. With respect to plantation activities, $36 \%$ of farmers involved in vegetable farming while about $25.6 \%$ were paddy and tobacco farmers. In addition, $12.8 \%$ of farmers involved with mixed farming consisted of paddy, vegetables and tobacco. The majority of farmers $(28.2 \%)$ have been farming in between 1 and 10 and 11-20 years. Moreover, majority of farmers $(64.1 \%)$ had pesticide spraying frequencies of more than 3 times in a month with most of them $(53.8 \%)$ spent between 1 to $12 \mathrm{~h}$ per month for

Table 3 Application of personal protective equipment (PPE) among farmers

\begin{tabular}{ll}
\hline PPE & $n=39(\%)$ \\
\hline Safety helmets & $35(89.7)$ \\
Yes & $4(10.3)$ \\
No & \\
Long-sleeve shirts & $35(89.7)$ \\
Yes & $4(10.3)$ \\
No & \\
Long Pants & $38(97.4)$ \\
Yes & $1(2.6)$ \\
No & \\
Eye goggles & $12(30.8)$ \\
Yes & $27(69.2)$ \\
No & \\
Nose mask & $33(84.6)$ \\
Yes & $6(15.4)$ \\
No & \\
Gloves & \\
Yes & $21(53.8)$ \\
No & $18(46.2)$ \\
Boots & \\
Yes & $28(71.8)$ \\
No & $11(28.2)$ \\
\hline
\end{tabular}

Table 4 Agriculture activities among farmers

\begin{tabular}{ll}
\hline Activities & Farmers \\
& $n=39(\%)$ \\
\hline Crops & $14(36.0)$ \\
Vegetables & $10(25.6)$ \\
Paddy & $10(25.6)$ \\
Tobacco & $5(12.8)$ \\
Combination of vegetables, paddy and tobacco & \\
Farming experiences & \\
Number of years & $11(28.2)$ \\
$1-10$ & $11(28.2)$ \\
$11-20$ & $8(20.5)$ \\
$21-30$ & $3(7.7)$ \\
$31-40$ & $6(15.4)$ \\
$41-50$ &
\end{tabular}

Frequencies of pesticides spraying and application of fertilizers

Frequency per month

Pesticides

$1-3$ times 14(35.9)

$>3$ times 25(64.1)

Fertilizers

1-3 times 30(76.9)

$>3$ times 9(23.1)

Duration of pesticides spraying and application of fertilizers

Spent hours per month

Pesticides

$1-12 \mathrm{~h}$

21(53.8)

$>12 \mathrm{~h}$

18(46.2)

Fertilizers

$1-4 \mathrm{~h}$

24(61.5)

$>4 \mathrm{~h}$

$15(38.5)$

Pesticides application equipments

Motorized knapsack sprayer 29(74.4)

Mechanical sprayer 5(12.8)

Other sprayer

$5(12.8)$

such activities. As for fertilizers exposure, most of farmers $(61.5 \%)$ spent about 1 to $4 \mathrm{~h}$ on fertilizers usage per month with majority (76.9 \%) exposed to fertilizers between 1 to 3 times per month. With regards to the type of pestiside applicators, farmers mostly used motorized knapsack sprayer $(74.4 \%)$ as compared to other methods. Meanwhile, with regards to common personal habits during and / or after pestiside exposure, majority of farmers $(>80 \%)$ showed a satisfactory practice on this aspect (Table 5).

The mean \pm S.D of micronucleus (MN) and binucleus $(\mathrm{BNu})$ per 1000 cells of farmers and controls are as 
Table 5 Personal habits during and/or after pesticides exposure

\begin{tabular}{ll}
\hline Personal habits & $\begin{array}{c}\text { Farmers } \\
n=39(\%)\end{array}$ \\
\hline Personal habits during pesticide applications & \\
Drinking & \\
Yes & $6(15.4)$ \\
No & $33(84.6)$ \\
Eating & \\
Yes & $5(12.8)$ \\
No & $34(87.2)$ \\
Smoking & \\
Yes & $3(7.7)$ \\
No & $36(92.3)$ \\
Post-pesticides application practices & \\
Change clothes & \\
Yes & $34(87.2)$ \\
No & $5(12.8)$ \\
Wash hand & \\
Yes & $37(94.9)$ \\
No & $2(5.1)$ \\
\hline
\end{tabular}

presented in Table 6. The frequency of MN was found to be significantly higher $(p<0.05)$ among farmers $(6.83$ $\pm 6.25)$ as compared to controls $(1.39 \pm 0.60)$. However, no significant difference was observed for the frequency of $\mathrm{BNu}$ between both groups.

The intra- (within) groups comparison of $\mathrm{MN}$ and $\mathrm{BNu}$ frequencies for age, gender, smoking status, BMI and duration of employment showed no significant difference. In contrast, inter-(between) groups comparison revealed a significantly higher $(p<0.05)$ frequency of MN among farmers as compared to control at every age group. Similarly, a significantly higher $(p<0.05)$ frequency of MN was observed among farmers as compared to control based on gender and smoking status. As for BMI classification, a significant difference $(p<$ 0.05 ) in the frequency of $\mathrm{MN}$ was only seen among normal and pre-obese of inter group comparison. A significant increase in $\mathrm{MN}$ frequencies $(p<0.05)$ was also detected for different duration of employment among farmers as compared to control. No significant difference was seen in the frequency of $\mathrm{BNu}$ for inter group comparison.

The correlation between $\mathrm{MN}$ and $\mathrm{BNu}$ frequencies with socio-demographic factors (age, years of employment, BMI) and duration of exposure to pesticides and fertilizers were studied. As shown in Table 7, a significant $(p<0.05)$ and positive correlation between the duration of fertilizers exposure and frequencies of $\mathrm{BNu}(r=$ $0.37, P=0.02)$ and $\mathrm{MN}$ were $(r=0.42, P=0.001)$ observed. However, no other correlation of various confounding factors on $\mathrm{MN}$ and $\mathrm{BNu}$ were observed (Table 7). The frequencies of $\mathrm{BNu}$ and $\mathrm{MN}$ show a weak positive correlation with the duration of pesticides exposure and the correlation was not significant $(p>0.05)$.

\section{Discussion}

Farmers who are exposed to pesticides are at greater risk for cytogenetic damage. To date, a number of studies have been carried out on the health status of pesticideexposed populations from different countries to elucidate the risk associated with pesticide-induced cytogenetic damage [7-10]. However, no definitive conclusions could yet be established on the association of these factors. Up to our knowledge, there have been no reports in Malaysia concerning the issue, suggesting the need for such studies to be conducted. In the present study, a preliminary investigation on cytogenetic damage among pesticides and fertilizers-exposed farmers from two rural areas of North East Malaysia, namely Bachok and Pasir Puteh was carried out. Cytogenetic damage was determined by the frequency of micronucleus (MN) and binucleus (BN) of isolated buccal epithelial cells. In order to identify the confounding factors that may contribute to cytogenetic damage, information on demographics, pesticide exposure and PPE application were also gathered.

The results obtained in this study showed a significant increase of $\mathrm{MN}$ frequencies in farmers when compared to controls. The results obtained for $\mathrm{MN}$ is in agreement with previous studies which observed higher frequency of MN among pesticide-exposed farmers than the nonexposed group [31-33]. Although some studies reported no significant increase in the $\mathrm{MN}$ frequencies in pesticide-exposed farmers $[25,30,34]$, the presence of $\mathrm{MN}$ as indicators for cytogenetic damage has been acknowledged as a useful biomonitoring tool in populations occupationally exposed to pesticides [35].

In contrast to $\mathrm{MN}$ results, $\mathrm{BNu}$ frequencies revealed no significant difference between the two studied groups. The result could be influenced by the presence of uncontrolled exogenous factors such as environmental influence that contributed in the evaluation of cytogenetic damages [36]. Moreover, a lack of comparable data in the literature concerning $\mathrm{BNu}$ frequencies as compared to $\mathrm{MN}$ indicated the unresolved role of $\mathrm{BNu}$ as a marker for nuclear abnormalities associated with pesticide toxicity.

Pesticides exposure has been linked to a number of human health effects $[37,38]$. Thus, an attempt was made to identify the possible chronic diseases and symptoms that are commonly associated with pesticide exposure among farmers. The number of farmers with reported hypertension, asthma, gastritis, insomnia, runny nose and coughing were higher as compared to 
Table 6 Frequencies of MN and BNu in farmers and controls according to age, gender, smoking status, BMI and duration of employment. Data are presented as mean \pm standard deviation (s.d)

\begin{tabular}{|c|c|c|c|c|}
\hline \multirow[b]{2}{*}{ Groups } & \multicolumn{2}{|l|}{$\begin{array}{l}\text { Controls }(n=30) \\
\text { Mean } \pm \text { S.D }\end{array}$} & \multicolumn{2}{|l|}{$\begin{array}{l}\text { Farmers }(n=39) \\
\text { Mean } \pm \text { S.D }\end{array}$} \\
\hline & Frequency of MN (\%) & Frequency of BNu (\%) & Frequency of MN (\%) & Frequency of BNu (\%) \\
\hline \multicolumn{5}{|l|}{ Age (years) } \\
\hline $26-35$ & $1.01 \pm 0.32$ & $2.01 \pm 0.73$ & $6.65 \pm 0.92^{*}$ & $1.50 \pm 1.41$ \\
\hline $36-45$ & $1.47 \pm 0.58$ & $1.67 \pm 0.94$ & $6.22 \pm 1.90^{*}$ & $1.51 \pm 0.19$ \\
\hline $46-55$ & $1.57 \pm 0.72$ & $1.49 \pm 0.86$ & $8.01 \pm 3.09^{*}$ & $1.33 \pm 0.45$ \\
\hline $56-65$ & $1.10 \pm 0.14$ & $1.85 \pm 0.64$ & $6.61 \pm 3.21^{*}$ & $1.63 \pm 0.74$ \\
\hline \multicolumn{5}{|l|}{ Gender } \\
\hline Male & $1.32 \pm 0.55$ & $1.85 \pm 0.86$ & $6.75 \pm 3.01^{*}$ & $1.49 \pm 0.61$ \\
\hline Female & $1.56 \pm 0.70$ & $1.32 \pm 0.70$ & $7.23 \pm 2.43^{*}$ & $1.80 \pm 0.83$ \\
\hline \multicolumn{5}{|l|}{ Smoking status } \\
\hline Smokers & $1.25 \pm 0.41$ & $1.99 \pm 1.08$ & $6.82 \pm 2.65^{*}$ & $1.39 \pm 0.62$ \\
\hline Non-smokers & $1.45 \pm 0.66$ & $1.56 \pm 0.71$ & $6.83 \pm 3.15^{*}$ & $1.65 \pm 0.65$ \\
\hline \multicolumn{5}{|l|}{$B M I$} \\
\hline Underweight & - & - & $6.89 \pm 3.04$ & $1.49 \pm 0.80$ \\
\hline Normal & $1.54 \pm 0.61$ & $1.59 \pm 1.19$ & $7.83 \pm 3.19^{*}$ & $1.43 \pm 0.77$ \\
\hline Pre-obese & $1.22 \pm 0.47$ & $1.72 \pm 0.62$ & $6.22 \pm 2.58^{*}$ & $1.58 \pm 0.57$ \\
\hline Obese grade 1 & $1.66 \pm 0.31$ & $1.30 \pm 0.61$ & $6.25 \pm 4.74$ & $1.85 \pm 0.35$ \\
\hline Obese grade 2 & $1.57 \pm 1.25$ & $2.23 \pm 0.91$ & - & - \\
\hline \multicolumn{5}{|c|}{ Duration of employment (years) } \\
\hline $1-10$ & $1.39 \pm 0.50$ & $1.74 \pm 0.99$ & $7.04 \pm 2.39^{*}$ & $1.34 \pm 0.61$ \\
\hline $11-20$ & $1.21 \pm 0.64$ & $1.74 \pm 0.72$ & $6.14 \pm 3.02^{*}$ & $1.54 \pm 0.42$ \\
\hline $21-30$ & $1.67 \pm 0.83$ & $1.56 \pm 0.93$ & $5.80 \pm 2.06^{*}$ & $1.76 \pm 0.48$ \\
\hline $31-40$ & $1.25 \pm 0.53$ & $1.63 \pm 0.52$ & $7.32 \pm 4.20^{*}$ & $1.29 \pm 0.88$ \\
\hline $41-50$ & - & - & $8.82 \pm 3.71$ & $1.71 \pm 1.08$ \\
\hline Total & $1.39 \pm 0.60$ & $1.69 \pm 0.84$ & $6.83 \pm 2.91^{*}$ & $1.54 \pm 0.64$ \\
\hline
\end{tabular}

*Farmers versus controls $(p<0.05)$

the control group. Moreover, more than $50 \%$ of farmers claimed frequent experience of eye irritation, blurred vision and numbness, suggesting a possible association to pesticide exposure. However, due to lack of medical history and nutritional status data, direct association of the manifested symptoms with pesticide exposure could not be established. Lack of PPE application during pesticide handling however can be one of the contributing factors for the reduced quality of health among the farmers.
The use of appropriate PPE should give a significant preventive impact in pesticide exposure among farmers. Significant increase in cytogenetic damage among farmers with no or little protective clothing during pesticide usage has been reported [39-41]. The usage of PPE, as observe in this study can be regarded as unsatisfactory. Of the 7 PPE assessed, only 4 of the PPE (safety helmets, long sleeved shirt, long pants and nose mask) were used by the majority of the farmers. Furthermore,

Table 7 Correlation between the frequencies of MN and BNu with the exposure to pesticides and fertilizers

\begin{tabular}{|c|c|c|}
\hline & $\begin{array}{l}\text { Frequency of MN } \\
(n=39)\end{array}$ & $\begin{array}{l}\text { Frequency of BNu } \\
(n=39)\end{array}$ \\
\hline \multirow[t]{2}{*}{ Duration of pesticides exposure (hours) } & 0.15 & 0.28 \\
\hline & $(p=0.37)$ & $(p=0.16)$ \\
\hline \multirow[t]{2}{*}{ Duration of fertilizers exposure (hours) } & 0.42 & 0.37 \\
\hline & $(p=0.001)^{*}$ & $(p=0.02)^{*}$ \\
\hline
\end{tabular}


the use of eye goggles, gloves and boots were considered low with a significant number of farmers who claimed that they never used these PPE throughout their farming activities which put them at greater risk of percutaneous exposure to pesticide. In a study conducted by Lander et al. [32], remarkable cytogenetic effects were noted in workers who did not use gloves, indicating the importance of PPE usage. Although the humid and hot climatic conditions in Malaysia could be the factor that limits the usage of full protective clothing [42, 43], continued effort to increase awareness among farmers on potential pesticide hazards and the importance of PPE usage can be useful to minimize pesticide related hazards at the workplace.

The presence of nuclear anomalies can be influenced by various confounding factors which include the exogenous (alcohol, diet, smoking and pesticide application) and endogenous (age and gender) factors [44-47]. Some studies have reported a positive age effect on MN frequencies among workers [33, 48]. However, in this study, no significant differences were seen on the frequencies of $\mathrm{MN}$ and $\mathrm{BNu}$ for both farmers and controls, which is in agreement to previously reported studies [34, 49].

Apart from age, the frequency of $\mathrm{MN}$ is also influenced by gender. Higher MN frequency in women than in men was commonly observed in populations without exposure to any physical or chemical agents, with $\mathrm{X}$ chromosome micronucleation being shown to contribute to the increase of MN frequency in women [44]. In this study however, no significant differences for the frequencies of $\mathrm{MN}$ and $\mathrm{BNu}$ between male and female subjects were observed, though increased $\mathrm{MN}$ frequency in female farmers were observed and is in accordance with a previous report [49].

Level of education may affect the level of knowledge and awareness on the safety of pesticide handling [50]. A previous study reported that the level of education with at least high school education is required for farmers to show a positive perception on the usefulness of PPE application [51]. In a study conducted among Brazilian farmers, the inability to understand the information displayed on products' labels led to increased exposure to pesticides [52]. A survey conducted on 61 randomly selected fruit-growers in a specific area of Turkey [53] revealed that pesticide practices were influenced by a number of characteristics, with those who consider pesticides as harmful consisted of farmers who are younger, better educated and have less experience in fruitgrowing. Our findings indicated that almost half of the farmers did not have formal education beyond the secondary education level. Therefore, levels of education may affect the perception they may have towards the harmfulness of the pesticides.
Tobacco smoke is a known genotoxicant and evidences on its ability to induce DNA damage have been comprehensively studied [45]. However, in this study the influence of smoking on cytogenetic damage showed no significant correlation as observed in the frequencies of $\mathrm{MN}$ and $\mathrm{BNu}$ between smokers and non- smokers within the pesticide exposed group. Similarly, the effect of smoking was not found in $\mathrm{MN}$ and $\mathrm{BNu}$ frequencies within the control group. The lack of association observed between the frequencies of studied nuclear anomalies and tobacco smoke exposure has been reported previously [30,54]. The effect of tobacco smoke exposure on genotoxicity is influenced by type of cigarettes and frequencies of smoking [54] both of which were not evaluated in this study. Thus, future studies focusing on gathering comprehensive information on smoking habits among farmers can provide more definitive correlation and conclusive evidence.

Duration of farming experience provides information on the degree of exposure to pesticide among farmers [4]. In a review by Bolognesi [14], occupational exposure to pesticide enhances genotoxic damage in a dosedependent manner. In this study, higher frequencies of $\mathrm{MN}$ were observed among farmers with farming experience of 41-50 years as compared to those with shorter durations of farming experience. However, the observed difference was not statistically significant. It appears that duration of farming activities demonstrated no significant influence on the frequency of $\mathrm{MN}$ and $\mathrm{BNu}$ among farmers, which is in agreement with other reported studies $[55,56]$. To date, studies on the association between pesticide exposure and frequency of $\mathrm{MN}$ and $\mathrm{BNu}$ are inconclusive. Eastmond [57] have indicated that the persistence of chromosomal damage is short-lived for acute exposure while Scarpato et al. [58] noted that damage may be reduced during low exposure periods for seasonal workers. However, increased chromosomal damage associated with duration of agricultural employment was reported by a number of studies $[17,58,59]$. The conflicting results from studies on pesticide-related cytogenetic damage were influenced by many factors such as the working environment, the studied populations, the type of exposure to pesticides such as seasonal application of pesticides, types of pesticide mixtures and the use of PPE [19, 60, 61]. Moreover, Bull et al. [4] has stated in a review that chromosomal damage itself is regarded as transient and sampling time play an important role on determining the accuracy of the data. Sampling should be done within 2 days following acute or cessation of chronic exposure to overcome false negative results. However, we have not considered this possibility which could contribute to our non-significant finding.

Assessments of correlation between $\mathrm{MN}$ and $\mathrm{BNu}$ frequencies with duration of pesticides and fertilizers 
exposures (hours) were also determined. The length of pesticide exposure had a positive correlation with $\mathrm{BNu}$ and $\mathrm{MN}$ frequencies, although the association was not statistically significant. However, there is a significant and positive correlation between the duration of fertilizers exposure and frequencies of $\mathrm{BNu}$ and $\mathrm{MN}$, suggesting a potential workplace hazard faced by the farmers. However, considering that this is a cross sectional study which has its limitation, no cause and effect could be established from the findings. Thus, the direct effects of pesticide and fertilizer exposures on the induction of nuclear abnormalities among exposed farmers could not be concluded at this stage of studies and warrant further investigation.

\section{Conclusion}

From our results, the pesticides and fertilizers usage in farming can contribute to the induction of cytogenetic damage. The role of age, sex, smoking and years of agriculture activities in $\mathrm{MN}$ and $\mathrm{BNu}$ frequencies were not evidenced and the result could be affected by small sample size. Thus, future studies would likely require assessment of much larger sample sizes to better characterize the effect of confounding factors in cytogenetic damage. It was notable that female farmers can be considered to be at higher risk for cytogenetic damage related to pesticide exposure as compared to male farmers. Increased exposure to fertilizers and pesticides and inappropriate use of PPE can be associated with increased cytogenetic damage. This finding can serve as a foundation for future biomonitoring studies in Malaysia.

\section{Competing interests}

The authors declare that there are no conflicts of interest.

\section{Authors' contributions}

ZAH, MFMZ, and NFR designed the study and performed data analysis. AH, SHL, NM, II, NZMS, HFO, ARG, MJMR participate in carried out field works, data analysis and subject sampling. MRMN contribute in sampling recruitment. ZAH, MFMZ, and NFR wrote the manuscript. All authors read and approved the final manuscript.

\section{Acknowledgments}

This work was supported by the Universiti Kebangsaan Malaysia under the Industry-Community Research Grant (Grant Number: Industri-2013-17). We thank the Malaysian Agriculture Research and Development Institute (MARDI) for their enormous contribution in the collection of samples from the farmers. Lastly, we wish to express our gratitude to everyone who participated in this study.

\footnotetext{
Author details

${ }^{1}$ Biomedical Science Program, School of Diagnostic and Applied Health Sciences, Faculty of Health Sciences, Universiti Kebangsaan Malaysia (UKM,), Jalan Raja Muda Abdul Aziz, Kuala Lumpur 50300, Malaysia. ${ }^{2}$ Horticulture Research Centre, MARDI, Persiaran MARDI-UPM, Serdang 43400, Selangor, Malaysia. ${ }^{3}$ Center for Neuroscience Services and Research (P3Neuro), Universiti Sains Malaysia, 16150, Kubang Kerian, Kota Baru, Kelantan, Malaysia.
}

Received: 25 August 2015 Accepted: 3 February 2016

Published online: 01 March 2016

\section{References}

1. International Agency for Research on Cancer. Occupational Exposures in Insecticide Application, and Some Pesticides. IARC Monographs on the Evaluation of Carcinogenic Risks to Humans. 1991; Vols 53.

2. Strong LL, Thompson B, Coronado GD, Griffith WC, Vigoren EM, Islas I. Health symptoms and exposure to organophosphate pesticides in farmworkers. Am J Ind Med. 2004;46:599-606.

3. Lauria L, Settimi L, Spinelli A, Figa'-Talamanca I. Exposure to pesticides and time to pregnancy among female greenhouse workers. Reprod Toxicol. 2006:22:425-30.

4. Bull S, Fletcher K, Boobis AR, Battershill JM. Evidence for genotoxicity of pesticides in pesticide applicators: a review. Mutagenesis. 2006;21:93-103.

5. Costello S, Cockburn M, Bronstein J, Zhang X, Ritz B. Parkinson's disease and residential exposure to maneb and paraquat from agricultural applications in the central valley of California. Am J Epidemiol. 2009;169:919-26.

6. Abdul Hamid Z, Harun Z, Lubis SH, Mohamed N, Ishak I, Othman HF, et al. Adoption of the mobile health screening programme for farming communities: a study among pesticide-exposed farmers from North East of Peninsular Malaysia. Malays J Health Sci. 2014;12:63-9.

7. Bolognesi C, Perrone E, Landini E. Micronucleus monitoring of a floriculturist population from wester Liguria, Italy. Mutagenesis. 2002;17:391-7.

8. Go'mez-Arroyo S, Di'az-Sa'nchez Y, Meneses-Pe'rez M, Villalobos-Pietrini R, Rodri'guez JL. Cytogenetic biomonitoring in a Mexican floriculture worker group exposed to pesticides. Mutat Res. 2002;466:117-24.

9. Shaham J, Kaufman Z, Gurvich R, Levi Z. Frequency of sister-chromatid exchange among greenhouse farmers exposed to pesticides. Mutat Res. 2001:491:71-80.

10. Padmavathi P, Prabhavathi PA, Reddy PP. Frequencies of SCEs in peripheral blood lymphocytes of pesticide workers. Bull Environ Contam Toxicol. 2000; 64:155-60.

11. Garaj-Vrhovac V, Zeljezic D. Cytogenetic monitoring of Croatian population occupationally exposed to a complex mixture of pesticides. Toxicology. 2001;165:153-62.

12. Jaga K, Dharmani C. Epidemiology of pesticide exposure and cancer: a review. Rev Environ Health. 2005;20:15-38.

13. Hagmar L, Brogger A, Hansten IL, Heim S, Hogstedt B, Knudsen L, et al. Cancer risk in humans predited by increased levels of chromosomal aberrations in lymphocytes: nordic study group on the health risk of chromosome damage. Cancer Res. 1994;54:2919-22.

14. Bolognesi C. Genotoxicity of pesticides: a review of human biomonitoring studies. Mutat Res. 2003;543:251-72.

15. Fenech M, Morley AA. Cytokinesis-block micronucleus method in human lymphocytes: effect of in vivo ageing and low dose X-irradiation. Mutat Res. 1986;161:193-8.

16. Viaggi S, Bonatti S, Abbondandolo A. New evidence for the presence of chromosomes in micronuclei of human and Chinese hamster cells. Mutagenesis. 1987;2:367-70.

17. Bolognesi C, Parrini M, Bonassi S, lanello G, Salanitto A. Cytogenetic analysis of a human population occupationally exposed to pesticides. Mutat Res. 1993;285:239-49.

18. Joksic G, Vidakovic A, Spasojevic-Tisma V. Cytogenetic monitoring of pesticide sprayers. Environ Res. 1997;75:113-8.

19. Falck GC, Hirvonen A, Scarpato R, Saarikoski ST, Migliore L, Norppa H. Micronuclei in blood lymphocytes and genetic polymorphism for GSTM1, GSTT1 and NAT2 in pesticide-exposed greenhouse workers. Mutat Res. 1999;441:225-37.

20. Garaj-Vrhovac V, Zeljezic D. Assessment of genome damage in a population of Croatian workers employed in pesticide production by chromosomal aberration analysis, micronucleus assay and Comet assay. J Appl Toxicol. 2002;22:249-55

21. Bhalli JA, Khan QM, Haq MA, Khalid AM, Nasim A. Cytogenetic analysis of Pakistani individuals occupationally exposed to pesticides in a pesticide production industry. Mutagenesis. 2006;21:143-8.

22. Bolognesi C, Carrasquilla G, Volpi S, Solomon KR, Marshall EJ. Biomonitoring of genotoxic risk in agricultural workers from five Colombian regions: association to occupational exposure to glyphosate. J Toxicol Environ Health A. 2009;72:986-97.

23. Ali T, Bhalli JA, Rana SM, Khan QM. Cytogenetic damage in female Pakistani agricultural workers exposed to pesticides. Environ Mol Mutagen. 2008;49: $374-80$.

24. Fenech M. The in vitro micronucleus technique. Mutat Res. 2000;455:81-95. 
25. Pastor S, Gutie'rrez S, Creus A, Xamena N, Piperakis S, Marcos R. Cytogenetic analysis of Greek farmers using the micronucleus assay in peripheral lymphocytes and buccal cells. Mutagenesis. 2001;16:539-45.

26. Rajkokila K, Shajithanoop S, Usharani MV. Nuclear anomalies in exfoliated buccal epithelial cells of petrol station attendants in Tamilnadu, South India. J Med Genet Genomics. 2010;2:18-22.

27. Holland N, Bolognesi C, Kirsch-Volders M, Bonassi S, Zeiger E, Knasmueller S, et al. The micronucleus assay in human buccal cells as a tool for biomonitoring DNA damage: The HUMN project perspective on current status and knowledge gaps. Mutat Res. 2008;659:93-108.

28. Rosin MP. The use of the micronucleus test on exfoliated cells to identify anti-clastogenic action in humans: a biological marker for the efficacy of chemopreventive agents. Mutat Res. 1992;267:265-76.

29. Cochran WG. Sampling techniques. 3rd ed. New York: Wiley; 1977.

30. Pastor S, Gutie'rrez S, Creus A, Cebuska-Wasilewska A, Marcos R. Micronuclei in peripheral blood lymphocytes and buccal epithelial cells of Polish farmers exposed to pesticides. Mutat Res. 2001:495:147-56.

31. Garaj-Vrhovac V, Zeljezic D. Evaluation of DNA damage in workers occupationally exposed to pesticides using single-cell gel electrophoresis (SCGE) assay. Pesticide genotoxicity revealed by comet assay. Mutat Res. 2000;469:279-85.

32. Lander F, Knudsen LE, Gamborg MO, Jarventaus H, Norppa H. Chromosome aberrations in pesticide-exposed greenhouse workers. Scand J Work Environ Health. 2000;26:436-42

33. Costa C, Teixeira JP, Silva S, Roma-Torres J, Coelho P, Gaspar J, et al. Cytogenetic and molecular biomonitoring of a Portuguese population exposed to pesticides. Mutagenesis. 2006;21:343-50.

34. Venegas W, Zapata I, Carbonell E, Marcos R. Micronuclei analysis in lymphocytes of pesticide sprayers from Concepción, Chile. Teratog Carcinog Mutagen. 1998;18:123-9.

35. Kirsch-Volders M, Fenech M. Inclusion of micronuclei in nondivided mononuclear lymphocytes and necrosis/apoptosis may provide a more comprehensive cytokinesis block micronucleus assay for biomonitoring purposes. Mutagenesis. 2001;16:51-8.

36. Hadnagy W, Seemayer NH. Cytotoxic and genotoxic effects of extract of particulate emission from a gasoline-powered engine. Environ Mol Mutagen. 1988;12:385-96.

37. Blair A, Freeman LB. Epidemiologic studies of cancer in agricultural populations: observations and future directions. J Agromedicine. 2009;14:125-31.

38. McCauley LA, Anger WK, Keifer M, Langley R, Robson MG, Rohlman D. Studying health outcomes in farmworker populations exposed to pesticides. Environ Health Perspect. 2006;114:953-60.

39. Carbonell E, Valbuena A, Xamena N, Creus A, Marcos R. Temporary variations in chromosomal aberrations in a group of agricultural workers exposed to pesticides. Mutat Res. 1995;344:127-34.

40. Pasquini R, Scassellati-Sforzolini G, Angeli G, Fatigoni C, Monarca S, Beneventi $L$, et al. Cytogenetic biomonitoring of pesticide-exposed farmers in central Italy. J Environ Pathol Toxicol Oncol. 1996;15:29-39.

41. Kourakis A, Mouratidou M, Kokkinos G, Barbouti A, Kotsis A, Mourelatos D, et al. Frequencies of chromosomal aberrations in pesticide sprayers working in plastic green houses. Mutat Res. 1992;279:145-8.

42. Lubis SH, Uttaman A, Nezrul Hisham AG, Jamil MRM, Inayat-Hussain SH. The current Perception Threshold among farmers in Muda, Kedah and fisherman in Setiu, Terengganu. In: Nashriyah BM, Ho NK, Ismail BS, Ali AB, Lum KY, Mansor MB, editors. Sustainable Rice Production in Malaysia Beyond 2000. Malaysia: MINT-MADA; 2002. p. 155-60.

43. Lubis SH, Sersi ME, Inayat-Hussain SH, Sakian NI, Salleh R, Jamil MRM, et al. A biomarker for exposure to organophosphate and carbamate pesticides. Asia Pac J Public Health. 2008;20:162-5.

44. Pastor S, Lucero L, Gutie'rrez S, Durba'n R, Go'mez C, Parro'n T, et al. A follow-up study on micronucleus frequency in Spanish agricultural workers exposed to pesticides. Mutagenesis. 2002;17:79-82.

45. Costa C, Silva S, Coelho P, Roma-Torres J, Teixeira JP, Mayan O. Micronucleus analysis in a Portuguese population exposed to pesticides. Preliminary survey. Int J Hyg Environ Health. 2007;210:415-8.

46. Fenech M, Neville S, Rinaldi J. Sex is an important variable affecting spontaneous micronucleus frequency in cytokinesis-blocked lymphocytes. Mutat Res. 1994;313:203-7.

47. Sivayoganathan C, Gnanachandran S, Lewis J, Fernando M. Protective measure use and symptoms among agropesticide applicators in Sri Lanka. Soc Sci Med. 1995;40:431-36.
48. Hwang SA, Gomez MI, Stark AD, St John TL, Pantea Cl, Hallman EM, et al. Safety awareness among New York farmers. Am J Ind Med. 2000;38:71-81.

49. Waichman AV, Römbke J, Ribeiro MO, Nina NC. Use and fate of pesticides in the Amazon State, Brazil: risk to human health and the environment. Environ Sci Pollut Res Int. 2002;9:423-8.

50. Sule I, Bulent M. Farmers' attitudes toward crop planning in Turkey. J Appl Sci. 2005:5:1489-95.

51. Husgafvel-Pursiainen K. Genotoxicity of environmental tobacco smoke: a review. Mutat Res. 2004;567:427-45.

52. Lucero L, Pastor S, Suare'z S, Durba'n R, Go'mez C, Parro'n T, et al. Cytogenetic biomonitoring of Spanish greenhouse workers exposed to pesticides: micronuclei analysis in peripheral blood lymphocytes and buccal epithelial cells. Mutat Res. 2000;464:255-62.

53. Bonassi S, Neri M, Lando C, Ceppi M, Lin YP, Chang WP, et al. Effect of smoking habit on the frequency of micronuclei in human lymphocytes: results from the human MicroNucleus project. Mutat Res. 2003;543:155-66.

54. Proia NK. Smoking and smokeless tobacco-associated human buccal cell mutations and their association with oral cancer-a review. Cancer Epidemiol Biomarkers Prev. 2006;15:1061-77.

55. Rupa DS, Reddy PP, Reddi OS. Analysis of sister-chromatid exchanges, cell kinetics and mitotic index in lymphocytes of smoking pesticide sprayers. Mutat Res. 1989:223:253-8.

56. Rupa DS, Reddy PP, Sreemannarayana K, Reddi OS. Frequency of sister chromatid exchange in peripheral lymphocytes of male pesticide applicators. Environ Mol Mutagen. 1991;18:136-8.

57. Eastmond DA. Benzene-induced genotoxicity: a different perspective. J Toxicol Environ Health A. 2000;61:353-6.

58. Scarpato R, Migliore L, Angotzi G, Fedi A, Miligi L, Loprieno N. Cytogenetic monitoring of a group of Italian floriculturists: no evidence of DNA damage related to pesticide exposure. Mutat Res. 1996;367:73-82.

59. Gomez-Arroyo S, Noriega-Aldana N, Osorio A, Galicia F, Ling S, VillalobosPietrini R. Sister-chromatid exchange analysis in a rural population of Mexico exposed to pesticides. Mutat Res. 1992;281:173-9.

60. Carbonell E, Xamena N, Creus A, Marcos R. Cytogenetic biomonitoring in a Spanish group of agricultural workers exposed to pesticides. Mutagenesis. 1993;8:511-7.

61. Dulout FN, Pastori MC, Olivero OA, Gonzalez Cid M, Loria D, Matos E, et al. Sister chromatid exchanges and chromosomal aberrations in a population exposed to pesticides. Mutat Res. 1985;143:237-44.

\section{Submit your next manuscript to BioMed Central and we will help you at every step:}

- We accept pre-submission inquiries

- Our selector tool helps you to find the most relevant journal

- We provide round the clock customer support

- Convenient online submission

- Thorough peer review

- Inclusion in PubMed and all major indexing services

- Maximum visibility for your research

Submit your manuscript at www.biomedcentral.com/submit

) Biomed Central 